\title{
Nitric oxide and histamine signal attempts to swallow: A component of learning that food is inedible in Aplysia
}

\author{
Ayelet Katzoff, Nimrod Miller, and Abraham J. Susswein ${ }^{1}$ \\ The Leslie and Susan Gonda (Goldschmied) Multidisciplinary Brain Research Center, The Mina and Everard Goodman Faculty \\ of Life Sciences, Bar Ilan University, Ramat Gan 52900, Israel
}

\begin{abstract}
Memory that food is inedible in Aplysia arises from training requiring three contingent events. Nitric oxide (NO) and histamine are released by a neuron responding to one of these events, attempts to swallow food. Since NO release during training is necessary for subsequent memory and NO substitutes for attempts to swallow, it was suggested that NO functions during training as a signal of attempts to swallow. However, it has been shown that $\mathrm{NO}$ may also be released in other contexts affecting feeding, raising the possibility that its role in learning is unrelated to signaling attempts to swallow. We confirmed that NO during learning signals attempts to swallow, by showing that a variety of behavioral effects on feeding of blocking or adding NO do not affect learning and memory that a food is inedible. In addition, histamine had effects similar to NO on learning that food is inedible, as expected if the transmitters are released together when animals attempt to swallow. Blocking histamine during training blocked long-term memory, and exogenous histamine substituted for attempts to swallow. NO also substituted for histamine during training. Histamine at concentrations relevant to learning activates neuron metacerebral cell (MCC). However, MCC activity is not a good monitor of attempts to swallow during training, since the neuron responds equally well to other stimuli. These findings support and extend the hypothesis that $\mathrm{NO}$ and histamine signal efforts to swallow during learning, acting on targets other than the MCC that specifically respond to attempts to swallow.
\end{abstract}

Classical and operant conditioning arise by pairing two contingent events, either a conditional and an unconditional stimulus or an operant and a reinforcer. However, complex learning and memory often depend on contingencies between three or more events. For example, learning and memory may be contextspecific (Squire and Kandel 2000), adding the contingency of the context to the other two events necessary for memory formation. Access to a relatively simple preparation displaying a variety of learning paradigms that arise from two contingent stimuli, as well as from more than two contingent stimuli, could provide insight into mechanisms that are common to simpler and more complex learning paradigms, as well as into mechanisms that distinguish complex paradigms from simpler learning processes.

Aplysia feeding is modified by both classical and operant conditioning procedures requiring two contingent stimuli. Classical conditioning arises from pairing a lip stimulus with a food that is eaten, or from pairing neural analogs of these stimuli (Lechner et al. 2000; Mozzachiodi et al. 2003). In operant conditioning a reinforcer is paired with a feeding response, or with neural analogs of a response (Nargeot et al. 1997; Brembs et al. 2002). Classical and operant conditioning procedures affect a common neural site in opposite ways (Lorenzetti et al. 2006).

Additional operant-like training paradigms also affect Aplysia feeding (Schwarz and Susswein 1986; Susswein et al. 1986; Schwarz et al. 1988, 1991; Chiel and Susswein 1993; Botzer et al. 1998; Katzoff et al. 2002, 2006; Cohen-Armon et al. 2004; Lyons et al. 2005). In these paradigms Aplysia are exposed to a palatable food that is difficult or impossible to consume. As a result of failed attempts to consume an inedible food, Aplysia decrease their

\footnotetext{
'Corresponding author.
}

E-mail avy@mail.biu.ac.il; fax 972-3-5352184.

Article is online at http://www.learnmem.org/cgi/doi/10.1101//m.1624610. responses to the food (Susswein et al. 1986). In contrast, successful consumption of a difficult food causes an increase in subsequent feeding responses (Susswein et al. 1986). Previous studies provided evidence that learning with inedible foods requires the contingency during training of three separable events: (1) chemical and mechanical stimuli signaling the food touching the lips (Schwarz et al. 1988); (2) stimuli signaling attempts to consume the food (Katzoff et al. 2006); (3) stimuli from the gut sensing that the attempts to consume the food have failed (Schwarz and Susswein 1986).

A previous report indicated that blocking nitric oxide (NO) release blocks memory after learning that food is inedible (Katzoff et al. 2002). NO and histamine are released together by neuron $\mathrm{C} 2$, which responds to attempts to consume the food (Chiel et al. 1986; Jacklet and Tieman 2004), one of the three contingent events that give rise to learning that food is inedible. It was hypothesized that NO is required for learning that food is inedible because its release signals attempts to swallow, the second of the three contingent stimuli required for memory formation. Data that support this hypothesis include: (1) exogenous NO substituted for attempts to swallow during training with inedible food (Katzoff et al. 2006); and (2) blocking NO transmission made ad libitum feeding less efficient and slowed rejection responses, presumably because animals are unable to monitor their efforts to swallow (Katzoff et al. 2006). Other than affecting rejection, neither blocking NO nor treatment with a NO donor was found to affect feeding or other behaviors (Katzoff et al. 2002, 2006).

A number of recent findings have found additional functions of NO signaling that could affect feeding behavior, raising the possibility that the function of NO in learning that food is inedible is unrelated to its signaling attempts to swallow. For example, treatment with a NO donor induces aspects of egg-laying (Miller et al. 2008), a behavior that is incompatible with feeding (Stuart 
and Strumwasser 1980; Ram 1982, 1983; Teyke et al. 1991). In addition, blocking NO release in quiescent animals induces food arousal (Miller et al. 2009), indicating that background NO release inhibits feeding. NO is also a transmitter in neurons functioning in the facilitation of withdrawal reflexes (Antonov et al. 2007), a component of sensitization of defensive behaviors that is also incompatible with feeding (Kupfermann and Pinsker 1968). In addition, nitrergic neurites are widely dispersed in the cerebral and buccal ganglia (Moroz 2006), raising the possibility that NO is a general regulator of feeding. Nitrergic neurons and neurites also innervate the esophageal sphincter in Helix (Serfözö et al. 2008), raising the possibility that they monitor opening and closing of the esophagus, which could be important in signaling success or failure to swallow.

This study systematically examines whether the role of NO in learning that food is inedible arises from these alternate functions of NO in regulating feeding. We found that the various additional functions of NO that affect feeding are unlikely to be related to the role of NO in learning that food is inedible, strengthening our previous hypothesis that NO functions to signal attempts to swallow in learning that food is inedible. We also examined the possible role of histamine, the other transmitter released by neuron $\mathrm{C} 2$, in learning that food is inedible and in feeding behavior. We found that histamine has effects on the learning paradigm that are identical to those of NO. In addition, histamine has effects on aspects of feeding not relevant to learning that differ from the effects of $\mathrm{NO}$, indicating that only the common effects of these transmitters are relevant to learning. These data provide strong support for the hypothesis that NO and histamine together signal efforts to swallow, one of the three events necessary for learning that food is inedible. We also examined whether the neuron MCC (giant metacerebral cell), which responds to NO and histamine released from neuron C2, might signal efforts to swallow in the context of learning that food is inedible. Our data rule out the possibility that MCC firing can specifically signal attempts to swallow during learning with inedible food.

\section{Results}

It was previously shown that NO has a role in signaling efforts to swallow (Chiel et al. 1986), one of the three contingent events necessary for memory formation after training with inedible food. It was therefore hypothesized that the role of NO in learning that food is inedible is signaling efforts to swallow (Katzoff et al. 2006). However, NO is now known to also affect additional aspects of Aplysia feeding. Our goal is to explore the possibility that NO may modulate memory after learning that food is inedible via some of these additional effects.

\section{Effect of NO on learning that food is inedible is not dependent on egg-laying}

Treatment with a NO donor initiates aspects of egg-laying behavior (Miller et al. 2008). When lip stimulation is paired with injection of a NO donor, animals learn that food is inedible, indicating that NO substitutes for attempts to swallow (Katzoff et al. 2006). However, memory arising from pairing a NO donor and stimulating the lips with food could be caused by NO initiating egg-laying, perhaps because egg-laying causes inhibition of feeding (Stuart and Strumwasser 1980; Ram 1982, 1983; Teyke et al. 1991), and lip stimuli become associated with inhibition of feeding. If this were so, pairing lip stimulation with agents other than NO that cause egg-laying should also cause memory that food is inedible. In contrast, if lip stimulation paired with a NO donor causes memory because the NO donor substitutes for attempts to swallow, agents causing egg-laying should not sub- stitute for attempts to swallow. We tested these possibilities. Experiments were performed on Aplysia fasciata.

As in previous experiments (Katzoff et al. 2006), one group of animals was trained and tested with inedible netted food. In two additional groups of animals, the lips were stimulated with netted food, but the food was withdrawn at each bite, thereby preventing the food from entering the mouth and inducing attempts to swallow. As in experiments examining the effects of exogenous NO application (Katzoff et al. 2006), lip stimulation was yoked to training that food is inedible in another animal. The lip stimulus was continued for a period that was yoked and was therefore identical to that required for cessation of responses in a matched experimental animal. Thus, the duration of the lip stimulation was determined by the time to stop in the trained animal, and the means and standard deviations of the training time in animals treated with lip stimulation were identical to those in animals trained with inedible food. Twenty-four hours after training or yoked lip stimulation, all of the animals were tested in a blind procedure, with inedible food that entered the mouth and elicited failed swallows, to test long-term memory. In place of injecting animals with a NO donor, which substitutes for entry of food into the mouth and attempts to swallow (Katzoff et al. 2006), but which also induces egg-laying (Miller et al. 2008), in one of the two groups of animals receiving lip stimulation, homogenates of the distal end of the large hermaphroditic duct (LHD) were injected $10 \mathrm{~min}$ before the start of lip stimulation. This tissue contains the homolog of the atrial gland of Aplysia californica, which contains peptides inducing egg-laying (Arch et al. 1978). LHD injections induced egg-laying with a latency of $\sim 20 \mathrm{~min}$. The other group was injected with artificial seawater (ASW). Memory was tested by examining the response of these animals $24 \mathrm{~h}$ later to netted food that was allowed to enter the mouth and elicit attempts to swallow.

There were no significant differences in the time to stop responding between the initial training session, and between the tests of memory after lip stimulation with and without the induction of egg-laying (Fig. 1). Since lip stimulation paired with egg-laying did not cause memory that a food is inedible, these data indicate that the ability of a NO donor to produce memory when paired with lip stimulation is unrelated to the egg-laying induced by the NO donor and is likely to be a result of NO substituting for attempts to swallow.

\section{Blocking nitrergic transmission does not block memory via effects on food arousal}

Treating a nonfeeding Aplysia with nitric oxide synthase (NOS) inhibitors, thereby lowering NO levels, induces food arousal expressed as increases in spontaneous biting (Miller et al. 2009), and also blocks memory after training with inedible food (Katzoff et al. 2002). The block of memory that food is inedible could be caused by the increased food arousal, rather than by the block of stimuli signaling attempts to swallow. If this were so, arousing the animals via a treatment other than a NOS inhibitor, such as food odor, should also block learning that food is inedible. We tested this possibility.

First, in A. fasciata, we compared the effects on food arousal of placing food into the water, and of treatment with the NOS inhibitor N $\omega$-nitro-L-arginine methyl ester (L-NAME), which blocks memory after training with inedible food (Katzoff et al. 2002). The number of bites elicited by each treatment was measured for $20 \mathrm{~min}$, which began $10 \mathrm{~min}$ after either the drug treatment, or after placing seaweed food in the water along with an animal. The animal and the food were separated by a mesh partition, preventing animals from contacting the food. There were no significant differences in biting (Fig. 2A) between animals 

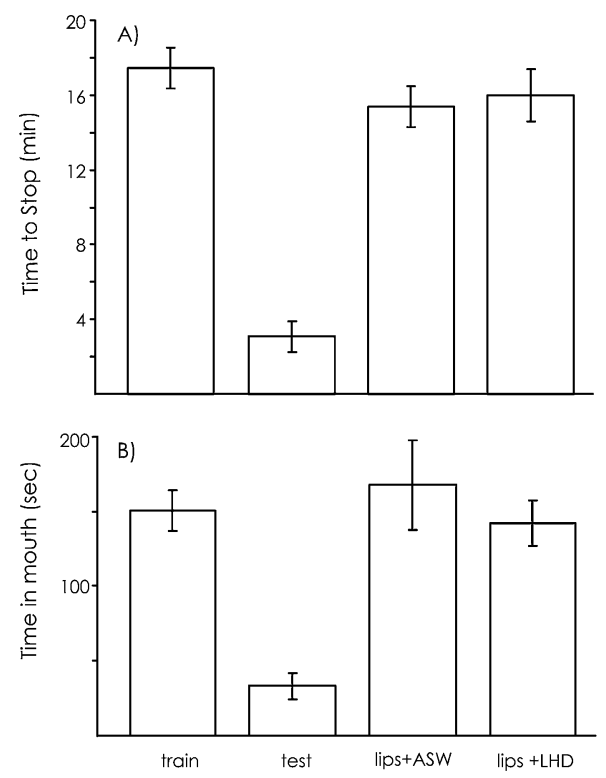

Figure 1. Lip stimulation plus egg-laying does not elicit memory that food is inedible. Animals $(n=6)$ were trained with inedible food. Each trained animal was yoked to animals whose lips were stimulated (for animals treated with LHD homogenate, and for animals treated with ASW; $n=6$ ) for a period equivalent to that of the training. Thus, the values for the initial training shown are for all treatments since treatments were yoked. Twenty-four hours later, both the trained and the yoked animals were tested with inedible netted food that entered the mouth and produced failed swallows. Significant differences were found between the four groups shown. (A) For time to stop: $P<0.001, F_{(3,20)}=35.61$. (B) For time in mouth: $P<0.001, F_{(3,20)}=10.61$; one-way analyses of variance. Naïve animals trained with inedible food and animals treated with the homogenate or with ASW and lip stimulation did not differ significantly from one another, but were significantly different from the 24-h test in animals previously trained with inedible food (StudentNeuman-Keuls test, $\alpha=0.05$ ). Means and standard errors are shown.

treated with L-NAME and animals treated with food, indicating that the two procedures are equally effective in inducing arousal. Next, we measured whether food arousal elicited by food odor could block memory after training with inedible food, as does treatment with L-NAME (Katzoff et al. 2002). Animals were trained with inedible food $10 \mathrm{~min}$ after placing the food into the water. The food remained present throughout the training session, and was removed after the training. Memory was then tested $24 \mathrm{~h}$ later. Training was similar to that in naïve controls not trained in the presence of seaweed. There was significant memory $24 \mathrm{~h}$ after the training, using two parameters of memory (Fig. 2B), indicating that arousing animals during training does not block the ability of animals to learn and remember that a food is inedible. Thus, the ability of L-NAME to block memory after training with inedible food (Katzoff et al. 2002) cannot be attributed to the arousing effects of L-NAME treatment, and is likely to arise because L-NAME blocks signals that Aplysia have attempted to swallow.

\section{Block of NO transmission blocks learning that food is edible}

When tough, inedible foods are eaten by Aplysia, the food enters the mouth, and animals attempt to swallow it. Stimuli from the esophageal nerves that innervate the gut provide information that the attempts to swallow have failed (Schwarz and Susswein 1986). The sphincter separating the gut from the buccal mass opens and then closes when animals swallow food, raising the possibility that the sphincter is monitored to determine whether attempts to swallow succeed or fail. Recent studies (Serfözö et al. 2008) have shown that nitrergic neurons and neurites innervate the esophageal sphincter in Helix. It is possible that blocking NO could block memory after learning with inedible food in part because NO has a role in signaling that swallowing has failed, rather than in signaling that there have been attempts to swallow.

Successfully swallowing a tough food causes learned changes of feeding that are opposite to those following failed attempts to swallow. When tested with an inedible food subsequent to previous training with edible tough food, Aplysia are more responsive than are naïve animals (Susswein et al. 1986). Learning that food is edible or inedible presumably arises via similar contingent stimuli, except that stimuli reporting on the success or failure of attempts to swallow provide opposite reinforcing stimuli. If NO release signals attempts to swallow and blocking of NO transmission blocks learning that food is inedible because of insufficient information on such efforts, one might expect that blocking NO transmission should also block learning that food is edible. In

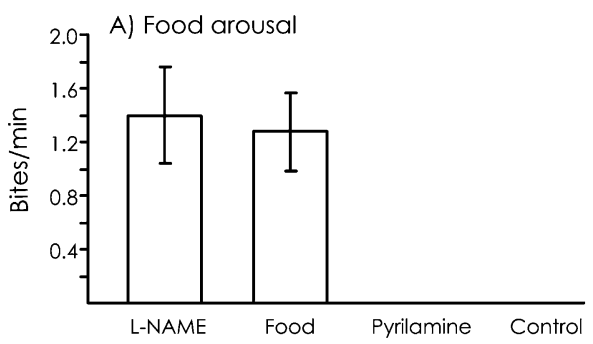

B) Training after food arousal
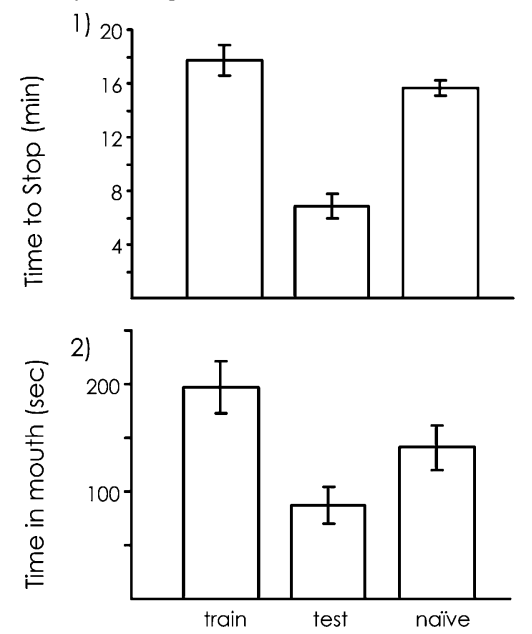

Figure 2. Food arousal does not block learning that food is inedible. $(A)$ Treatment with L-NAME and placing food in the environment both induce food-finding and biting. Bites per minutes resulting from L-NAME treatment were not significantly different from the bite rate elicited by food in the environment $\left(P=0.81, t_{(8)}=0.24\right.$; two-tailed $t$-test $)$. In contrast, control untreated animals did not bite, and treatment with the histamine blocker pyrilamine also did not induce bites. (B) Arousing animals with food in the environment does not affect learning that food is inedible, indicating that the effects of L-NAME on the learning are not the result of its causing food arousal. Animals that were trained after being exposed to food in the water from $10 \mathrm{~min}$ prior to the training and throughout the training learned well, and showed good memory, as measured by savings in (1) the time to stop responding to food $(P<$ $\left.0.001, t_{(4)}=11.44\right)$, and in (2) the time that food was in the mouth during the first $5 \mathrm{~min}\left(P=0.009, t_{(4)}=4.62\right.$; two-tailed paired $t$-tests $)$. Data are shown for the training and testing sessions of animals trained with food in the environment, as well as for naive controls tested in a blind procedure with those previously trained with food. 
contrast, if $\mathrm{NO}$ is released by signals monitoring success or failure in the attempts to swallow, the transmitter would be unlikely to signal both success and failure, and learning after successful swallowing would not be affected by blocking NO transmission. We examined these possibilities.

A. fasciata were trained with edible netted food (the seaweed Ulva). Before training, they were treated with either ASW or with the NOS blocker L-NAME. Twenty-four hours later, memory was tested with inedible netted food. The behavior of animals treated with ASW and with L-NAME was compared to that of naïve animals (Fig. 3).

Animals that had been trained with ASW required a significantly longer time to stop responding to the food during subsequent testing than did animals trained with L-NAME or the naïve (untrained) animals. Also, animals trained with ASW held the food in their mouths for a significantly greater portion of the first 5 min of exposure than did animals in the other two groups. These data confirm that training with edible food causes an increase in responsiveness when animals are exposed to the inedible food (Susswein et al. 1986). The data also indicate that blocking NO transmission during training with edible food blocks memory after training, as it blocks memory after training with inedible food (Katzoff et al. 2002). These findings support the contention that the role of NO in learning that food is edible or inedible is to signal attempts to swallow, a necessary component of both types of learning, rather than signaling the failure to
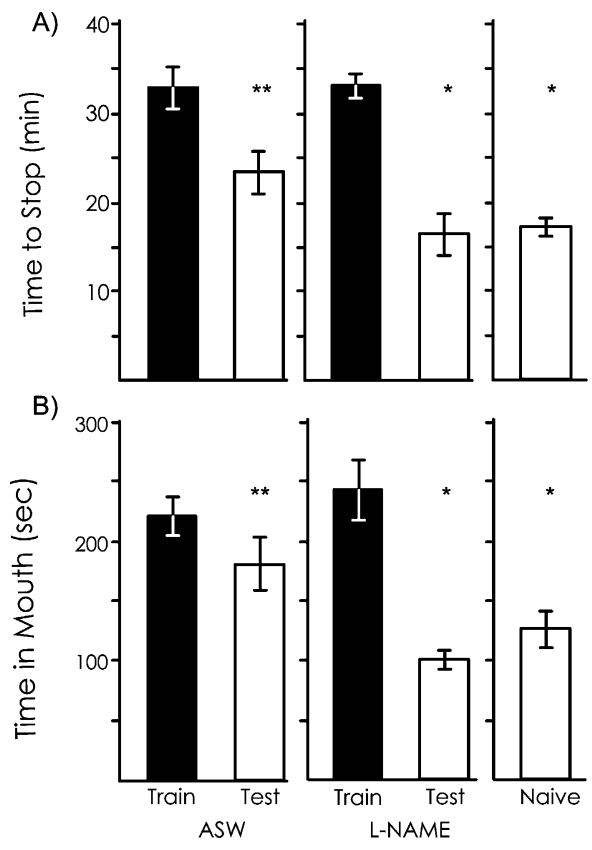

Figure 3. L-NAME blocks memory after learning that a food is edible. Training with edible food was performed after treatment with either ASW or with L-NAME. Animals were tested with inedible netted food $24 \mathrm{~h}$ later, and the results were compared to those in naïve animals exposed to inedible food. Means and standard errors are shown. A one-way analysis of variance showed significant differences between animals trained with ASW and L-NAME and naïve animals, in both $(A)$ the time to stop $(P=$ $\left.0.019, F_{(2,18)}=4.989\right)$ and $(B)$ the time that food was in the mouth for the first 5 min $\left(P=0.008, F_{(2,18)}=6.348\right)$. Post hoc tests (Student-NeumanKuels) showed that at $\alpha=0.05$, the values in animals trained with ASW were significantly higher than those trained with L-NAME, or naïves, with no significant difference between animals trained with L-NAME and naïves. Thus, L-NAME blocked memory after training with edible food. In both $A$ and $B$, columns marked with $\left(^{*}\right)$ are not significantly different from one another, but are significantly different from the column marked with $\left(^{* *}\right)$. swallow, a component of learning that food is inedible, but not a component of learning with edible food.

NO release can also facilitate withdrawal responses (Antonov et al. 2007), which are inconsistent with feeding (Walters et al. 1981). In addition, NO is released by tissue damage (Lewin and Walters 1999). Learning that food is inedible could conceivably arise by pairing lip stimulation with aversive stimuli resulting from failure to swallow. Our finding that blocking NO also blocks learning with edible food effectively rules out this possible explanation of the role of NO in learning.

\section{NO does not substitute for conspecifics}

Exogenous NO paired with lip stimulation leads to memory that food is inedible. Nitrergic neurites are widely distributed in the buccal and cerebral ganglia (Moroz 2006), raising the possibility that NO functions in setting levels of food arousal, or may be a general facilitator of feeding. Exogenous NO may mimic these functions, and thereby may allow memory to be formed in situations that would otherwise not cause memory, such as when the lips are touched with food but the food does not enter the mouth. Increases in arousal or modulation of feeding could explain how a NO donor paired with lip stimulation, a stimulus that alone is unable to cause memory, nonetheless elicits memory (Katzoff et al. 2006).

We tested the possibility that NO is a general facilitator of memory formation by examining whether exogenous NO rescues memory after a training session in which memory formation is blocked. If $\mathrm{NO}$ is a facilitator of memory formation, exogenous NO should cause memory after training Aplysia in an environment that blocks memory formation. In contrast, if the role of NO in memory specifically is to signal attempts to swallow, exogenous NO should not save memory in animals trained in such an environment.

Previous data have shown that in $A$. fasciata pheromones released by conspecifics strongly modulate learning and memory that food is inedible. When animals are maintained in isolation, preventing them from sensing pheromones released by conspecifics, the training is ineffective in causing long-term memory (Schwarz et al. 1991). However, pre-arousing animals with food can restore the ability to learn in isolated animals (Schwarz and Susswein 1993). Does treatment with NO rescue memory in animals trained in isolation?

Ten minutes prior to training, isolated animals were treated with either a NO donor, $S$-nitroso- $N$-acetylpenicillamine (SNAP) or ASW. After the training, the animals were restored to cages in which a conspecific was present behind a barrier. Memory was tested $24 \mathrm{~h}$ later in the presence of a conspecific. Parameters during the test of memory were compared to those in naïve, previously untrained animals that were continuously maintained in the presence of a conspecific. There were no significant differences in the time to stop responding to food or in the time that food was in the mouth, between animals previously trained in isolation with or without SNAP, or in naïve animals (Fig. 4). These data confirm that animals trained in isolation show no long-term memory and also indicate that exogenous NO does not rescue memory after training in isolation. Thus, the role of $\mathrm{NO}$ in memory formation is not explained by its possible role as a mediator of arousal or as a general facilitator of memory formation, and it presumably substitutes for attempts to swallow that occur after food has entered the mouth because it signals such attempts during training.

\section{Histamine and memory}

Previous reports (Chiel et al. 1990) indicated that C2, a nitrergic neuron in the Aplysia feeding system, responds to food in and 

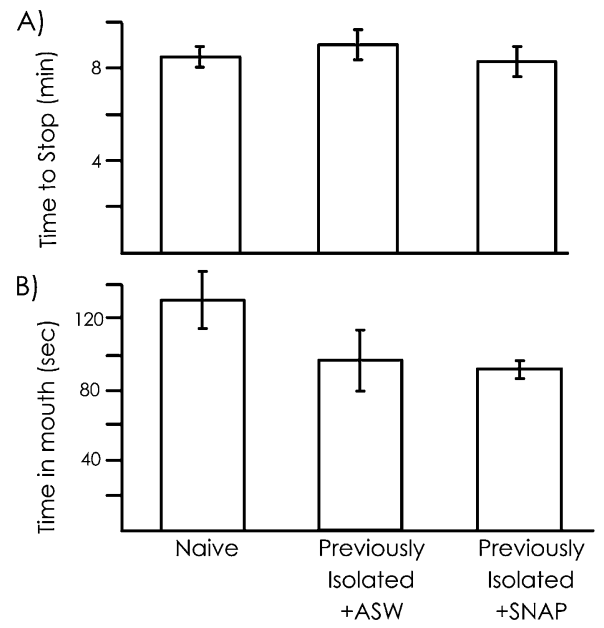

Figure 4. NO does not restore memory in isolated Aplysia. Memory that food is inedible was tested in animals that were trained $24 \mathrm{~h}$ earlier in isolation. Animals were either treated with ASW $(N=5)$ or with the NO donor SNAP $(N=6)$. The data were compared to those from a naive, previously untrained animal $(N=5)$. Means and standard errors are shown. There was no significant difference in $(A)$ the time to stop responding $\left(P=0.7, F_{(2,13)}=0.364\right)$ or $(B)$ the time that food was in the mouth during the first $5 \mathrm{~min}\left(P=0.11, F_{(2,13)}=2.58\right.$; one-way analyses of variance) between the three groups. Thus, treatment with SNAP did not restore the ability of training in isolation to produce long-term memory.

around the mouth and to active feeding responses. The neuron would be activated by strong efforts to swallow food, such as those initiated during training with edible and inedible foods (Chiel et al. 1986). In addition to releasing NO, the neuron also releases histamine. NO and histamine together excite postsynaptic followers (McCaman and Weinreich 1985; Chiel et al. 1986; Weiss et al. 1986b; Jacklet 1995; Jacklet and Tieman 2004). If the role of $\mathrm{NO}$ in learning that food is inedible is to signal efforts to swallow, one might expect that histamine would have a similar role. In contrast, if NO affects learning because it mediates other signals, one might expect that histamine and NO should affect feeding behavior and learning in different ways. We examined these possibilities.

\section{Block of histamine transmission blocks memory}

The histamine $\mathrm{H} 1$ blocker pyrilamine blocks the effects of histaminergic neuron C2 on one of its followers (Jacklet et al. 2005). To test the effect of blocking histamine transmission on long-term memory after learning that food is inedible, A. californica were treated with either the histamine inhibitor pyrilamine or with ASW. As in previous studies, $10 \mathrm{~min}$ after the drug treatment, animals were trained with inedible netted Ulva and memory was tested $24 \mathrm{~h}$ later. During the initial training animals treated with pyrilamine, as well as those treated with ASW, responded readily to the inedible netted food. There was no significant difference between pyrilamine- and ASW-treated animals in the time that food was in the mouth during the first $5 \mathrm{~min}$ of training, or in the time needed for animals to stop responding to food during training. Thus, similar to the effect of blocking NO transmission, the block of histamine had minimal effects on the training (Fig. 5).

As in previous experiments, long-term memory was examined by re-exposing the animals to the same inedible food $24 \mathrm{~h}$ after the initial training and then comparing the time spent in the mouth during the first $5 \mathrm{~min}$ of the training and testing sessions, as well as comparing the time to stop responding in the two sessions. There were significant decreases in both parameters for animals treated with ASW. In contrast, there were no significant differences in these parameters in animals treated with pyrilamine, indicating that the $\mathrm{H} 1$ inhibitor blocked long-term memory formation (Fig. 5). These data indicate that blocking of both $\mathrm{NO}$ and histamine transmission have similar effects on long-term memory after learning that food is inedible, as would be expected if both transmitters are released together from neurons responding to efforts to swallow.

\section{Lip stimulation paired with histamine causes long-term memory}

Exogenous NO substitutes for attempts to consume food when Aplysia are trained with inedible food. When the lips are stimulated with food that does not enter the mouth, thereby preventing animals from attempts to swallow, animals do not learn that food is inedible. However, treatment with a NO donor while the lips are stimulated causes subsequent memory identical to that following learning that food is inedible. Neither NO alone nor lip stimulation alone caused memory (Katzoff et al. 2006).

Does exogenous histamine paired with lip stimulation also cause subsequent memory? To test this possibility, A. californica were treated with exogenous histamine, with and without stimulating the lips. In addition, the effects of lip stimulation alone were examined in controls that were treated with ASW in place of histamine. As in experiments examining the effects of exogenous $\mathrm{NO}$ application, lip stimulation was yoked to training that food is inedible in another animal. Long-term memory was then tested $24 \mathrm{~h}$ later.

Histamine had major effects on many aspects of Aplysia behavior. Immediately after injection with histamine, animals began to perform seemingly random movements of various parts of the body for $\sim 5 \mathrm{~min}$. The body extended and then contracted. Simultaneous with these movements, folds often formed within the skin. The folds moved over the surface of the skin. The pathological behaviors in response to histamine gradually subsided, and animals were superficially normal by $10 \mathrm{~min}$ after the treatment. Nonetheless, they did not respond to food placed on the lips.
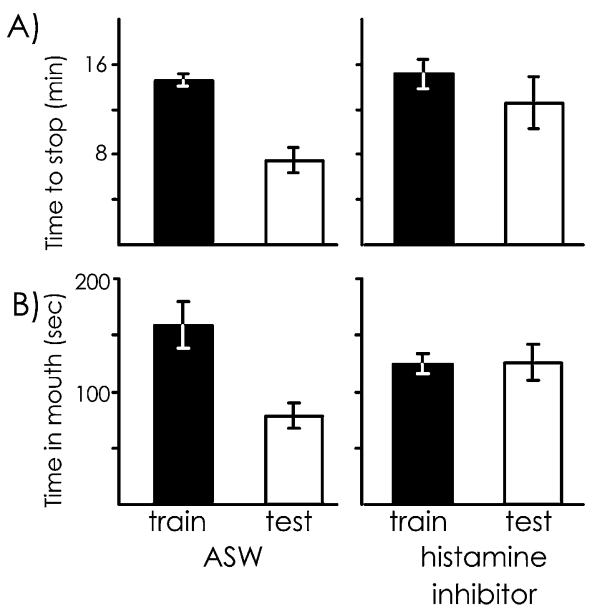

Figure 5. Blocking of histamine transmission with the $\mathrm{H}_{1}$ blocker pyrilamine blocks subsequent long-term memory. Animals treated with ASW prior to training showed normal memory $24 \mathrm{~h}$ later, as shown by $(A)$ decreases in time to stop responding to food $\left(P<0.01, t_{(7)}=7.09\right)$, as well as for $(B)$ the time that food was in the mouth during the first $5 \mathrm{~min}(P=$ $\left.0.01, t_{(7)}=3.36\right)$. In contrast, animals treated with the $H_{1}$ blocker pyrilamine showed no memory, as shown by a lack of savings in time to stop responding to food $\left(P=0.57, t_{(7)}=0.60\right)$, as well as for the time that food was in the mouth during the first $5 \mathrm{~min}\left(P=0.70, t_{(7)}=0.40\right.$; two-tailed paired $t$-tests). Means and standard errors are shown. 
Animals were treated with either histamine or ASW. Ten minutes later, the lips were stimulated with netted food. Histaminetreated animals did not respond to the food, but the food was nonetheless maintained in contact with the lips. ASW-treated animals responded to the food, but the food was not permitted to enter the mouth. As in previous experiments, the food was briefly withdrawn at each response of the animal. Animals treated with lip stimulation were yoked to the animals that received normal training with the inedible food entering the mouth. The yoked procedure was performed for both histamine- and ASW-treated animals. Twenty-four hours after training or yoked lip stimulation, all of the animals were tested in a blind procedure, with inedible food that entered the mouth and elicited failed swallows, to test long-term memory (Fig. 6).

For animals treated with seawater, after $24 \mathrm{~h}$ significant differences were observed between the animals that had been trained with food entering the mouth and those in which the lips alone were stimulated, for both the time to stop responding to food as well as for the time that food was in the mouth during the first $5 \mathrm{~min}$ of the test. In contrast, $24 \mathrm{~h}$ after lip stimulation coupled with histamine, animals showed decreases in the time that food spent in the mouth during the first $5 \mathrm{~min}$ and in the time to stop responding to food, comparable to those after training when food did enter the mouth. In addition, injection of histamine alone, without lip stimulation, did not lead to a reduction of the response to food $24 \mathrm{~h}$ later. These data indicate that neither lip stimulation alone nor treatment with histamine alone led to longterm memory that a food is inedible. However, the combination of lip stimulation paired with histamine led to long-term memory identical to that following training with inedible food. These data suggest that histamine substitutes for an essential component of

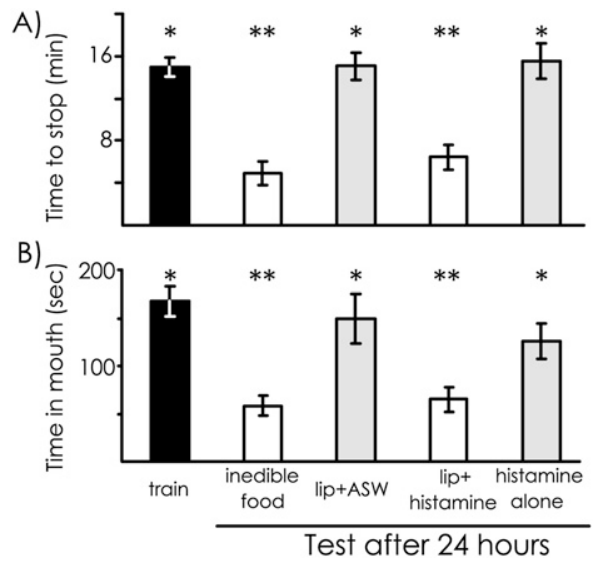

Figure 6. Lip stimulation coupled with histamine leads to long-term memory. Animals $(n=8)$ were trained with inedible food. Each trained animal was yoked to an animal whose lips were stimulated (for histaminetreated, $n=8$; seawater-treated, $n=8$ ) for a period equivalent to that of the training. Thus, the values for the initial training shown are for all treatments since treatments were yoked. Twenty-four hours later, both the trained and the yoked animals were tested with inedible netted food that entered the mouth and produced failed swallows. Significant differences were found between the five groups shown. $(A)$ For time to stop: $P<0.001, F_{(4,35)}=17.221$. (B) For time in mouth: $P<0.001, F_{(4,35)}=$ 8.09 ; one-way analysis of variance. Animals previously trained with inedible food and animals treated with histamine + lip stimulation did not differ significantly from one another, but were significantly different from the other three groups, which also did not differ significantly from one another (Student-Neuman-Keuls test, $\alpha=0.05$ ). Means and standard errors are shown. For both $A$ and $B$, the three columns marked with (*) are not significantly different from one another, but are significantly different from the two columns marked with $\left(^{* *}\right)$. These two columns are also not significantly different from one another. training, entry of food into the mouth and attempts to swallow, as does NO.

\section{Inhibiting histamine affects feeding behavior}

A previous study showed that the block of NO transmission during ad libitum feeding leads to a decrease in the efficiency of feeding, as shown by an increase in the time required to consume a specific quantity of food (Katzoff et al. 2006). The decreased efficiency of feeding was interpreted as arising from a relative inability of the animals to sense efforts to consume food. An adaptive response to increased effort is to reject the food and try to bite and swallow at a different location. When NO synthesis was blocked, animals persisted in ineffective efforts to swallow in place of rejecting food and trying at a different site on the food (Katzoff et al. 2006). This interpretation was consistent with findings using food or nonfood stimuli that selectively elicit bite, swallow, or rejection responses. Inhibiting NO synthesis had no effects on bite or swallow amplitude or frequency (Katzoff et al. 2002), but rejection responses became less regular (Katzoff et al. 2006).

If histamine is released along with $\mathrm{NO}$ and signals efforts to feed, blocking histamine transmission should also make ad libitum feeding less efficient. To examine the effects of blocking histamine on ad libitum feeding, we treated animals (A. californica) with the histamine blocker pyrilamine at a concentration that blocks histaminergic transmission (Fig. 7).

Previously food-deprived animals were allowed $1.5 \mathrm{~h}$ of ad libitum access to food. There was no significant difference between animals treated with pyrilamine or with ASW in the quantity of food eaten. However, the time devoted to feeding was significantly increased in animals treated with pyrilamine. Thus, blocking of histamine transmission decreased the efficacy of feeding, since animals needed to spend more time feeding to eat the same quantity of food. These data were similar to those after treatment with a NOS blocker and are consistent with the hypothesis that NO and histamine are released together in response to efforts at swallowing food.

The data in Figure 2A shows that blocking NO transmission and food odor in the water both induce food arousal, as shown by increased biting. Does block of histamine also cause increased food arousal? To test this possibility, $A$. fasciata were treated with pyrilamine and the number of bites was measured for $20 \mathrm{~min}$, which began $10 \mathrm{~min}$ after the drug treatment. Pyrilamine did not elicit biting (Fig. 2A). These data indicate that NO and histamine do not act together in controlling food arousal, although both transmitters signal attempts to swallow and are both necessary for long-term memory after training with inedible food. It is likely that the common effects of NO and histamine on signalingattempted swallows are relevant to learning, rather than the different effects of these transmitters on food arousal.

\section{NO substitutes for histamine}

Our data suggest that NO and histamine have similar effects on Aplysia feeding behavior, presumably because both are released by attempts to swallow. In learning and memory that food is inedible, does one transmitter substitute for the other?

Previous work has shown that when memory is blocked with L-NAME, injecting the animals with the NO donor SNAP compensates for the block of NO signaling and allows long-term memory formation (Katzoff et al. 2002). We examined whether NO also compensates for the block of histamine transmission with pyrilamine. In this experiment, all animals were treated with pyrilamine $10 \mathrm{~min}$ before training with inedible food. In one group of animals, the NO donor SNAP was injected along with the pyrilamine, whereas the other group of animals received pyrilamine alone. The volume injected into the animals was the same in both groups. As in the previous experiments (Fig. 5), animals 

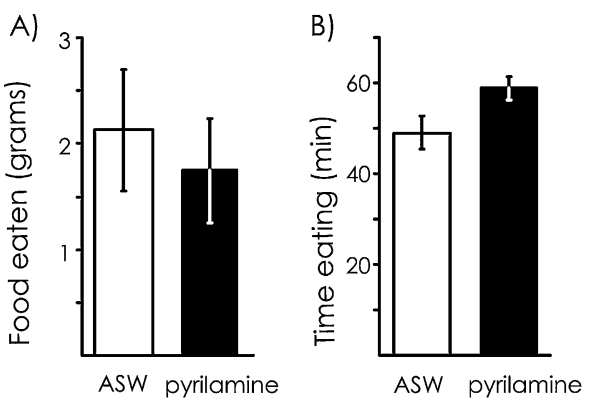

Figure 7. Block of histamine transmission with pyrilamine reduces feeding efficacy. Means and standard errors are shown. $(A)$ There was no significant difference in the quantity of food eaten between animals treated with ASW and those treated with pyrilamine $\left(P=0.53, t_{(17)}=0.65\right.$; two-tailed $t$-test). (B) In contrast, animals treated with pyrilamine spent significantly more time feeding than did animals treated with ASW $(P=$ $0.02, t_{(17)}=2.64$; two-tailed $t$-test).

treated with pyrilamine alone displayed no long-term memory, as shown by a lack of significant savings in either the time to stop responding to the food or in the time that food was in the mouth during the first $5 \mathrm{~min}$ (Fig. 8). In contrast, animals treated with pyrilamine and SNAP showed significant long-term memory, as evidenced by significant savings in both parameters $24 \mathrm{~h}$ after the training (Fig. 8). These data indicate that an addition of NO compensates for a lack of histamine in learning that food is inedible.

\section{Histamine excites a follower of C2}

Attempts to consume food excite neuron C2 (Chiel et al. 1986, 1990), which releases both histamine and NO. C2 excites the MCC neuron of the cerebral ganglion via release of both histamine and NO (Jacklet and Tieman 2004). Application of a NO donor at a concentration causing memory when paired with lip stimulation was found to cause MCC firing (Katzoff et al. 2006). Does histamine at a concentration that induces learning when paired with lip stimulation also excite the MCC? We examined this question by driving the MCC with carbamyl choline (CCh), and determining whether the CCh-induced activity was amplified by histamine (Fig. 9).

Bathing the cerebral ganglion in CCh mimics the effects of lip stimulation (Susswein et al. 1996), probably because lip afferents conveying information about food to the cerebral ganglion use acetylcholine (ACh) as their transmitter. Touching food to the lips of animals initiates bites (Kupfermann 1974), and application of CCh drives repeated buccal motor programs (Susswein et al. 1996), which are correlates of bites. In an isolated cerebral ganglion from A. californica, we measured the response of the MCC to applications of CCh that induce buccal motor programs. MCC spikes were readily identified, since they are the largest amplitude spikes in the connective. We then applied histamine to the ganglion and observed the activity of the MCC in the presence and absence of CCh. As in previous experiments (Susswein et al. 1996), the application of CCh to the cerebral ganglion caused the MCC to fire. Histamine significantly amplified the effect of CCh on the MCC, although its effects were weaker than those of the NO donor SNAP (see Fig. 6 in Katzoff et al. 2006). There was no obvious difference in the latency of MCC activity in the presence and absence of histamine. The presence of histamine alone produced little or no increase in firing over the background level (data not shown).

\section{Possible involvement of MCC in learning}

The findings that the MCC is driven by NO (Katzoff et al. 2006) and histamine (Fig. 9) at concentrations that cause memory when paired with lip stimulation raises the possibility that the MCC specifically responds to efforts to swallow food, and the response of the MCC is used as a monitor of such efforts during training with edible and inedible foods. Previous studies have shown that the MCC fires when Aplysia become aroused by food, and MCC activity is a monitor of food arousal (Kupfermann and Weiss 1982). Stimuli such as lip stimulation alone arouse animals and also cause MCC firing (Horn et al. 1999), but are not sufficient for learning that food is inedible. How could MCC activity distinguish between lip stimulation alone and lip stimulation accompanied by attempts to swallow a tough food? It is possible that the MCC firing frequency is increased over that caused by lip stimulation alone when animals attempt to swallow a tough food, and the increased MCC firing in response to tough food might signal attempts to swallow, and might mediate some of the responses to such efforts. We tested this possibility by recording from the MCC in freely behaving animals. The responses to rhinophore and lip stimulation with netted food were compared to the MCC response when animals attempted to swallow the netted food (Fig. 10). With respect to background firing when no food was present, the MCC fired significantly more during rhinophore and lip stimulation, as well as during attempts to swallow netted food. However, there was no significant difference in the firing rate in response to attempted swallows than in response to lip or rhinophore stimulation. These findings confirm that the MCC fires in response to stimuli causing food arousal. The data also indicate that MCC firing could not be used as a reliable monitor of attempts to swallow, since it is not activated by attempts to swallow over its activation by other arousing stimuli. If C2 or pharmacologically similar neurons signal attempts to swallow in the context of learning that food is inedible via release of NO and histamine, they do so via outputs to neurons other than the MCC.

\section{Discussion}

Learning that a food is edible or inedible arises from complex experiences. Food stimulates the lips, eliciting bites. Food then
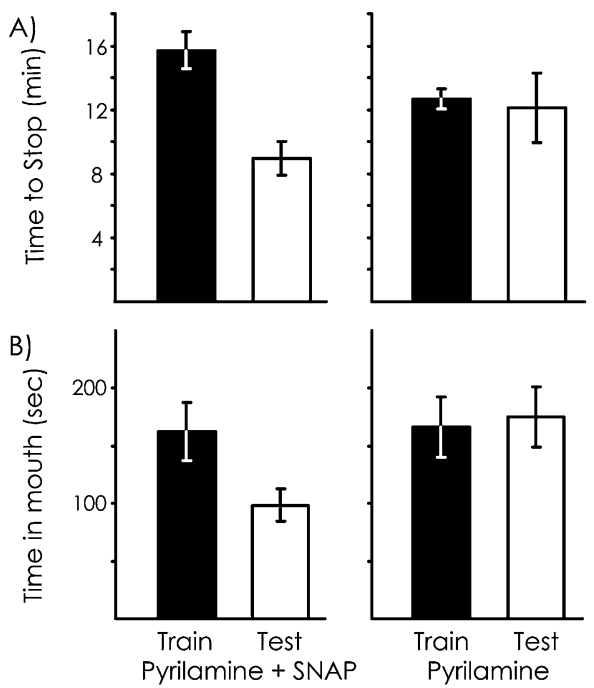

Figure 8. NO substitutes for histamine in memory formation. Histamine transmission during training was blocked by treating animals with the $\mathrm{H}_{1}$ histamine blocker pyrilamine. When tested $24 \mathrm{~h}$ later, these animals showed no savings in either $(A)$ the time to stop responding to the food $\left(P=0.85, t_{(6)}=0.12\right)$ or $(B)$ the time that food was in the mouth during the first $5 \mathrm{~min}\left(P=0.76, t_{(6)}=0.32\right)$. In contrast, animals treated with the NO donor SNAP showed significant savings in the time to stop responding to the food $\left(P=0.001, t_{(5)}=6.62\right)$ and the difference in time that food was in the mouth during the first $5 \mathrm{~min}$ approached significance $\left(P=0.08, t_{(5)}=2.16\right.$; two-tailed paired $t$-tests for all comparisons). Means and standard errors are shown. 


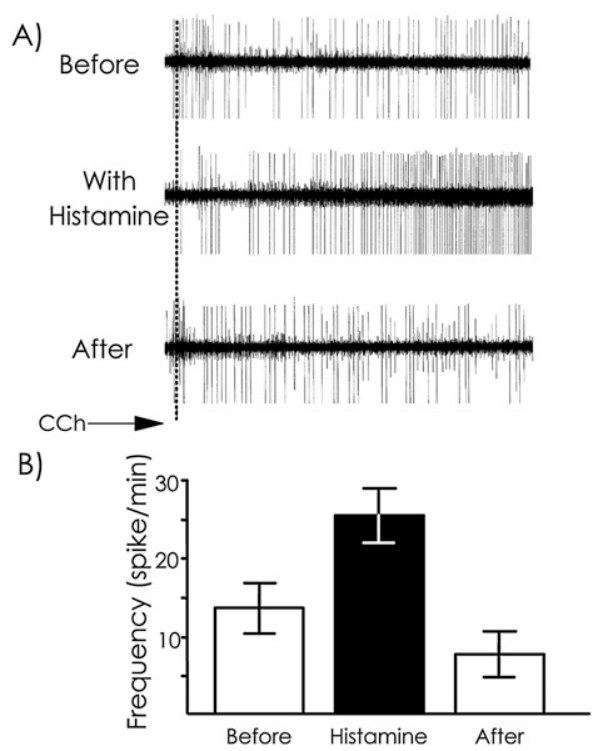

Figure 9. Exogenous histamine amplifies MCC activity induced by CCh. CCh was applied for $10 \mathrm{~min}$, with 10-min intervals of rest between applications. Each animal was tested with a total of eight CCh applications. Histamine was applied along with the fourth application of CCh. Histamine remained in the bath until after the end of the fifth application of CCh. The data labeled "Before" are from the third application of CCh. The data labeled "With histamine" are from the fifth application of CCh. The data labeled "After" are from the seventh application of CCh. $(A)$ Examples of histamine activity recorded extracellularly in response to $\mathrm{CCh}$ before the application of histamine, in the presence of histamine, and after the histamine was removed. The MCC axon is the largest in the cerebro-buccal connective, and the large spikes in the figure are MCC spikes. There was virtually no firing of the MCC in the absence of CCh, both with and without histamine, and therefore the records begin just before the application of CCh. CCh induces firing after a delay, but the onset of increased firing was difficult to measure, and was not quantified. (B) Means and standard errors for all preparations $(N=4)$ for the MCC firing frequency during the third ("Before"), fifth ("Histamine"), and seventh ("After") application of CCh. There was a significant increase in firing frequency in the presence of histamine $\left(P=0.03, t_{(3)}=3.7\right.$, twotailed paired $t$-test).

enters the mouth, eliciting attempts to swallow that succeed or fail to transport food into the gut. During the learning, animals gradually stop responding to the food. Animals then remember that a food is edible or inedible for minutes to days (Susswein et al. 1986; Schwarz et al. 1991; Botzer et al. 1998). Learning with inedible food is dependent on the presence of background stimuli that maintain the arousal state of the animals, such as pheromones secreted by conspecifics or egg cordons in A. fasciata (Schwarz et al. 1988, 1991).

\section{A triple contingency gives rise to learning that food is inedible}

Data in this report, as well as previously published data, indicate that learning and memory with inedible foods depend on three separable stimuli that occur contingent with one another: (1) stimulation of the lips with food; (2) food entry into the mouth, and efforts to swallow; and (3) failure of the attempt to swallow.

\section{Stimulation of the lips with food}

Memory after learning that food is inedible is taste-specific (Schwarz et al. 1988), indicating that plasticity is at least partially localized to a pathway responding differentially to different tastes. In addition, NO (Katzoff et al. 2006) or histamine (Fig. 6) treatments cause long-term memory only when paired with lip stimu- lation, indicating that lip stimulation is a necessary component of the learning.

\section{Food entry into the mouth and efforts to swallow}

Activation of taste receptors is not sufficient for memory formation. Food must enter the mouth and elicit attempts to swallow (Schwarz et al. 1988). In the absence of such efforts, lip stimulation can cause memory that food is inedible only if animals are treated with exogenous NO (Katzoff et al. 2006) or histamine (Fig. 6), indicating that these transmitters substitute for efforts to swallow.

\section{Failure of the attempt to swallow}

Lip stimulation and attempts to swallow are also not sufficient for memory formation. Gut input must also inform the animal that attempts to swallow have succeeded or failed. The esophageal nerves signal that animals have failed in their attempts to swallow. The role of the nerves in signaling failure is shown by the finding that bilateral lesions of both major branches of the esophageal nerves block learning and memory that food is inedible, because signals for failure are missing (Schwarz and Susswein 1986).

\section{Function of $\mathrm{NO}$ and histamine in learning that food is inedible}

Previous studies have identified a neuron using both NO and histamine as its transmitters that fires in response to active feeding movements. This neuron, C2, excites the giant MCC (Weiss et al. 1986b; Jacklet 1995; Jacklet and Tieman 2004), as well as additional cerebral ganglion neurons (McCaman and Weinreich 1985; Chiel et al. 1986). The presence of a neuron activated by efforts to swallow that releases both $\mathrm{NO}$ and histamine provides support for the hypothesis that these transmitters are released together as a result of efforts to swallow inedible food during learning, and this release is necessary for memory formation. Additional support for the hypothesis that NO and histamine function together in signaling effort comes from the findings that blocking of either NO (Katzoff et al. 2002) or histamine (Fig. 5) blocks memory formation; that either NO (Katzoff et al. 2006) or histamine (Fig. 6) can substitute for efforts to swallow during training with inedible food; and that exogenous NO can replace histamine during learning (Fig. 8).

Although blocking of either NO or histamine transmission blocked memory formation, application of either transmitter alone with lip stimulation caused memory. The sufficiency of either transmitter probably arises because the concentrations used are likely to be higher than those released during training. The

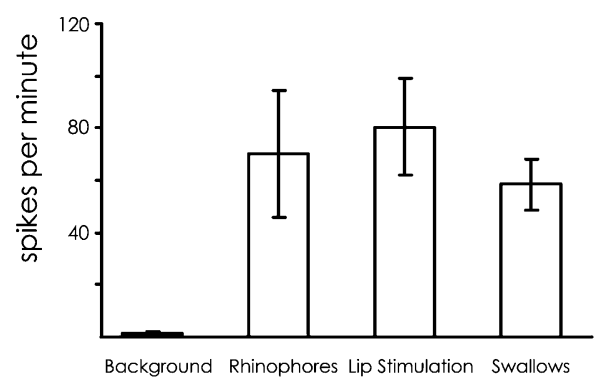

Figure 10. $M C C$ firing in the absence of any stimulus (background), as well as in response to stimulation of the rhinophores and lips with netted food. In addition, the MCC activity was measured in response to attempts to swallow the netted food. MCC firing during the three treatments was compared to that without any stimulus. Results are pooled from recordings in five animals. Means and standard errors are shown. There was no significant difference in the firing rate in response to attempted swallows, or rhinophore, or lip stimulation $\left(P=0.65, F_{(2,9)}=0.45\right.$; oneway analysis of variance). 
finding that an application of NO can compensate for blocking histamine supports this hypothesis.

In addition to being necessary for memory formation, increased efforts to swallow also affect other aspects of Aplysia feeding. When animals feed ad libitum on complex, natural foods, an increase in the effort to swallow can signal a switch from ingestive to egestive feeding behaviors (Katzoff et al. 2006). Egestion of a tough natural food is functionally useful, since after food is egested the animal is free to bite and swallow at a different site on the food, thereby increasing the efficiency of ad libitum feeding. A previous study showed that the block of NO transmission makes ad libitum feeding less efficient, by partially blocking the ability to switch from ingestion to egestion (Katzoff et al. 2006). Blocking of histamine transmission also leads to a decrease in the efficacy of ad libitum feeding (Fig. 7), providing further support for the hypothesis that the release of NO and histamine together signals efforts to swallow food.

In addition to being released by efforts to swallow, both $\mathrm{NO}$ and histamine have other functions at other neural sites. Application of exogenous NO or histamine, or a block of these transmitters, uncovered behavioral correlates of some of these functions. We examined systematically whether some of the other effects of NO or histamine could explain the role of these transmitters in learning that food is inedible. We found that they could not.

\section{Additional effects of NO}

The ability of NO to substitute for attempts to swallow in training could not be attributed to a possible arousing effect of NO release on feeding, or to the possibility that NO produces a general facilitation of memory formation, since NO did not substitute for another treatment that inhibits memory formation-isolation during training (Fig. 4). Also, the ability of NO to substitute for attempts to swallow could not be attributed to induction of egglaying by NO (Miller et al. 2008), and the inhibition of feeding by egg-laying (Stuart and Strumwasser 1980; Ram 1982, 1983; Teyke et al. 1991), since other treatments causing egg-laying did not substitute for NO in causing memory (Fig. 1). In addition, exogenous histamine did not cause egg-laying, but did substitute for NO in causing memory (Fig. 6).

Although blocking nitrergic transmission causes increased food arousal (Fig. 2A; Miller et al. 2009), this effect could not account for the block of memory formation caused by blocking nitrergic transmission during training. Food in the environment, which also caused arousal, did not block learning that food is inedible, whereas blocking histaminergic transmission did not cause food arousal, but did block memory after training (Fig. 2B). Thus, the arousing effects of blocking nitrergic transmission are unrelated to the function of this transmitter during learning that food is inedible.

\section{Additional effects of histamine}

Treatment with histamine strongly affected many aspects of Aplysia behavior and prevented the animals from feeding. The response to histamine was probably pathologic, reflecting the excitation of many neurons that do not usually work together. Nonetheless, histamine paired with lip stimulus caused long-term memory (Fig. 6). This finding shows that active bites in response to food, which occur in normal learning that food is inedible, do not contribute to the subsequent memory.

The findings that exogenous NO or histamine paired with lip stimulation cause long-term memory also show that the activation by histamine or by NO of many neurons not relevant to the learning did not interfere with the memory obtained by activating the subset of neurons relevant to memory formation.

\section{Learning with edible foods}

Training with a difficult but edible food causes an increase in feeding responses (Fig. 3). This learning paradigm has been much less thoroughly examined than has training with inedible food. Our data are consistent with the hypothesis that learning with edible food also arises from a triple contingency. Thus, NO transmission is needed for learning that food is edible (Fig. 3), presumably because it signals attempts to swallow, which are a necessary component of learning. Successful swallowing is presumably signaled by the esophageal nerves. In other learning paradigms affecting Aplysia feeding, the esophageal nerves have a key role in learning (Nargeot et al. 1997, 2007; Lechner et al. 2000; Mozzachiodi et al. 2003; Brembs et al. 2004; Lorenzetti et al. 2006). In both classical and operant conditioning, esophageal nerve stimuli contingent on other stimuli lead to increased feeding. Stimulation of the esophageal nerves is a positive reinforcer in operant conditioning tasks or is an unconditional stimulus in classical conditioning tasks. In addition, cutting the esophageal nerves blocks an appetitive classical conditioning task (Lechner et al. 2000).

Studies by others have shown that NO facilitates withdrawal responses (Antonov et al. 2007), which are inconsistent with feeding (Walters et al. 1981). NO is also released by tissue damage (Lewin and Walters 1999). These observations raise the possibility that NO functions in learning that food is inedible because prolonged attempts to swallow tough foods are aversive (perhaps continued attempts to swallow irritate the radula) and the NO and histamine released during this aversive state sensitize or facilitate sensory neurons that can inhibit feeding behavior. However, the finding that $\mathrm{NO}$ also has a key role in learning that food is edible, in which feeding responses are increased, is inconsistent with this hypothesis. The hypothesis is also inconsistent with the finding that after training with inedible food, the food does not elicit defensive responses such as escape locomotion, respiratory pumping, or inking, as do other stimuli that are paired with noxious stimuli (Levy and Susswein 1999).

\section{$\mathrm{C} 2$ and $\mathrm{MCC}$}

C2 is an unconventional sensory neuron (Weiss et al. 1986a) responding to active feeding movements, particularly in response to tough foods. It is likely to respond to increases in the toughness of a food (Chiel et al. 1986, 1990). Followers of C2 innervate muscles that are active during the retraction phase of swallows, and contribute to swallowing (Chiel et al. 1986). C2 releases both NO and histamine, which together excite the MCC (Weiss et al. 1986b; Jacklet 1995) as well as additional cerebral ganglion neurons (McCaman and Weinreich 1985; Chiel et al. 1986), suggesting that $\mathrm{NO}$ and histamine may be relevant to learning that food is edible or inedible because $\mathrm{C} 2$ is critically involved in these learning paradigms. However, it is important to note that additional nitrergic (Moroz 2006) and histaminergic (Elste et al. 1990) neurons are present in the cerebral and buccal ganglia, and these could also have major roles in learning that food is inedible, either in addition to or in place of $\mathrm{C} 2$.

If $\mathrm{C} 2$ has a role in learning that food is inedible, activation of the MCC could also be important. The MCC is a serotonergic neuron having widespread effects in the buccal ganglia (Kupfermann et al. 1979), and changes in the activity of the MCC as a result of attempts to swallow could potentially have a role in the initiation of long-term memory. Changes in expression of an isoform of nitric oxide synthase accompany reward learning leading to longterm memory in the CGN neuron, the homolog of the MCC in Lymnaea (Korneev et al. 2005), indicating that this neuron may have a critical role in long-term memory formation in this system. However, chronic recordings from the MCC indicate that the firing frequency of this neuron cannot have a role in signaling 
efforts to swallow. Although we found that attempts to swallow inedible netted food elicited MCC activity, equivalent activity was also elicited by rhinophore and lip stimulation (Fig. 10). Information specifically relevant to attempts to swallow may be conveyed by other followers of $\mathrm{C} 2$ or by other neurons responding to NO and histamine release during the efforts.

\section{$\mathrm{NO}$ and histamine in learning and memory}

$\mathrm{NO}$ is associated with memory formation in many other systems (for review, see Susswein et al. 2004). NO transmission may be required during training (Robertson et al. 1995; Katzoff et al. 2002), or only after training, when memory is consolidated (Baratti and Kopf 1996; Kemenes et al. 2002); NO may be necessary for a number of memory stages following training (e.g., Katzoff et al. 2002), or for only one stage (e.g., Müller 1996); it can also have a role in memory reconsolidation (Baratti et al. 2008); and it can act via the cGMP cascade (Bredt and Snyder 1992), or via additional mechanisms (Meffert et al. 1996; Ahern et al. 2002; Edwards and Rickard 2007).

Histamine is also involved in learning and memory tasks such as spatial, fear, and passive avoidance learning (Bacciottini et al. 2001; Eidi et al. 2003; Bernaerts et al. 2004; Baldi et al. 2005; Komater et al. 2005).

In many systems in which NO or histamine is implicated in learning and memory, these are transmitters in neurons central to the plastic changes underlying learning. However, in learning that food is inedible, NO and histamine have a role in one of three input pathways whose contingent activation is required for memory.

\section{Cellular basis of learning a triple contingency}

Studies of learning on a cellular level often examine the interaction between two signals giving rise to pairing-specific changes in neurons thought to underlie associative learning (Squire and Kandel 2000). However, learning that food is edible or inedible, as well as many other complex learning tasks, depends on a triple contingency. Although there is a rich literature on how pairingspecific changes in neurons may be modulated by a third event (e.g., McGaugh 2004), the cellular mechanisms underlying behavioral change dependent on a triple contingency have not been explored. It is possible that two separate pairing-specific events are needed to give rise to a change in behavior requiring a triple contingency. Alternatively, it is possible that all three events must interact at a single neural site to give rise to a behavioral change.

Classical and operant conditioning tasks depending on two contingent events affect Aplysia feeding (Nargeot et al. 1997, 2007; Lechner et al. 2000; Brembs et al. 2002, 2004; Mozzachiodi et al. 2003; Lorenzetti et al. 2006). In these tasks, an unconditional stimulus or a reinforcer from the esophageal nerve is paired with a conditional stimulus or an operant, or with their neural analogs. Unlike learning that food is edible or inedible, these learning paradigms do not depend on entry of food into the mouth and efforts to swallow. Our finding that efforts to swallow are a key component of learning with edible and inedible foods, and that such efforts are signaled by NO and histamine, potentially allows us to examine how classical and operant conditioning differ from learning that a food is edible or inedible. Since the classical and operant conditioning paradigms that have been identified are not dependent on entry of food into the mouth and feedback from attempts to swallow, one would predict that classical and operant conditioning of feeding is unlikely to depend on NO or histamine, whereas the learning paradigms developed in our laboratory do depend on these transmitters. NO and histamine presumably call into play circuit elements needed for learning with edible and inedible foods, but not for classical and operant conditioning. Access to the neural circuit underlying Aplysia feeding will allow us to compare the cellular mechanisms underlying learning and memory requiring a double versus triple contingency.

\section{Materials and Methods}

\section{Animals}

Most of the experiments were performed on A. californica weighing 80-120 g purchased from Marinus, Marinus Scientific, and Santa Barbara Marine Bio. The experiment testing the effects of isolation on learning and memory, the experiment on edible foods, the experiments on egg-laying, and the experiments on the effects of pre-arousing animals were performed on $A$. fasciata that were collected along the Mediterranean coasts of Israel. Both species learn and remember equally well, and the choice of which species to use was dependent on seasonal availability. A. fasciata were used during the summer months, when A. californica are often not healthy. As described for previous experiments (Botzer et al. 1998; Katzoff et al. 2002, 2006), animals were maintained five to six to a cage immersed in 1300-L tanks of aerated, filtered Mediterranean seawater at $18^{\circ} \mathrm{C}$. Animals were fed every 3-4 d with Ulva lactuca that was gathered along the Mediterranean coast of Israel and kept frozen in the laboratory. Animals were maintained on a 12-h light-dark cycle. Since A. californica are diurnally active and $A$. fasciata are nocturnally active (Kupfermann 1968; Susswein et al. 1983; Lyons et al. 2005), experiments on $A$. californica were performed during the day phase of the cycle, whereas experiments on A. fasciata were performed during the night phase.

Animals were separated from each other $1 \mathrm{wk}$ before an experiment. They were thereafter kept in individual cages and were food-deprived. As in numerous previous studies examining learning that food is inedible in Aplysia (Botzer et al. 1998; Katzoff et al. 2002, 2006), $24 \mathrm{~h}$ before an experiment, they were transferred to 10-L experimental aquaria that were maintained at room temperature $\left(23^{\circ} \mathrm{C}\right)$. In all but one experiment, they were kept two to an aquarium, with the two animals separated by a partition allowing the flow of water. In one experiment testing the effect of isolation, animals were kept one to a cage during the $24 \mathrm{~h}$ preceding training, as well as during the training. After the training they were transferred to an aquarium containing a conspecific behind a partition, and memory was tested $24 \mathrm{~h}$ later.

\section{Training and testing memory-blinds}

All tests of memory were performed using a blind procedure. The identity of an animal and its previous treatment during training was coded, and the experimenter learned the identity only after all animals used in the experiment had been tested.

\section{Training with inedible food}

Training was identical to that used in many previous studies (Botzer et al. 1998; Katzoff et al. 2002, 2006). Aplysia responded to Ulva wrapped in plastic net that was touched to the rhinophores by lifting the head and centering the food on the lips. This stimulus induced biting, which led to food entry into the mouth. Animals then attempted to swallow the food. However, the netted food physically could not be swallowed, and it became lodged in the buccal cavity, producing repetitive failed swallowing responses (Susswein et al. 1986; Schwarz et al. 1988; Chiel and Susswein 1993; Botzer et al. 1998; Katzoff et al. 2002; Lyons et al. 2005). Food eventually left the buccal cavity, probably because it was actively egested. The experimenter continued to hold the food against the lips, inducing further biting responses, entries into the mouth, and failed swallows. This was continued until the end of the experiment. As training proceeded, many bites failed to cause entry of food into the mouth. When food did enter the mouth, it stayed within for progressively shorter periods, eliciting fewer attempted swallows. The criterion for cessation of a training session was $3 \mathrm{~min}$ in which food stimulated the lips without it entering the mouth (Botzer et al. 1998). Biting responses and entry and exit of food in and out of the mouth were observed visually, and their occurrences were noted by pressing the appropriate 
button of a three-button mouse connected to a computer. A computer program noted the time that the mouse button was touched.

Memory was shown in a test session that was identical to the initial training session (Schwarz and Susswein 1986; Susswein et al. 1986; Schwarz et al. 1988, 1991; Botzer et al. 1998). Memory was displayed by a decreased responsiveness during the first $5 \mathrm{~min}$ of the test session, with respect to the start of the original training session, and by a reduction from the training to the test session in the time to the criterion to stop the experiment (Susswein et al. 1986; Chiel and Susswein 1993; Botzer et al. 1998).

\section{Training with edible food}

Edible netted food was prepared by opening a hole in the apex of the netted food used to train animals that food was inedible (Susswein et al. 1986). The animals were able to pull the food out of the net and then swallow. After the food had been removed by the animal, the animal was stimulated with a second net containing food. This training was continued for $40 \mathrm{~min}$. During this period, animals consumed a mean of $0.15 \mathrm{~g}$. Twenty-four hours after the training, animals were tested with inedible netted food in a procedure identical to that used for training and testing with inedible food. Memory was displayed by an increase in responsiveness during the first 5 min of the test session, with respect to the start of a training session in a naïve animal, and by an increase in the time to stop responding to food, with respect to that in a naïve animal (Susswein et al. 1986).

\section{Training with lip stimulation}

Ulva wrapped in plastic net was touched to the rhinophores. When the animal lifted the head and the lips were seen, food was touched to the lips, eliciting bites. The food was briefly withdrawn at each bite, thereby preventing it from entering the mouth and eliciting attempts to swallow. This procedure does not lead to learning or memory that the food is inedible (Schwarz et al. 1988; Katzoff et al. 2006). The lip stimulus was continued for a period that was yoked to and was therefore identical to that required for cessation of responses in a matched experimental animal. Thus, the duration of the lip stimulation was determined by the time to stop in the matched trained animal, and therefore the means and standard deviations for the trained and stimulated animals were the same. Twenty-four hours after training or yoked lip stimulation, all of the animals were tested with inedible food that entered the mouth and elicited failed swallows, to test the efficacy of the previous training procedure in producing either long-term memory.

\section{Food arousal}

The number of bites was used as a measure of food arousal. Hungry animals were transferred to an aerated observation tank $24 \mathrm{~h}$ before the start of the experiment. The number of bites performed was measured during a 20-min observation, which began 10 min after treatment (either placing seaweed into the water behind a partition, or injection with L-NAME or pyrilamine).

\section{Ad libitum feeding}

Animals that were previously food-deprived for $1 \mathrm{wk}$ were given ad libitum access to U. lactuca. Before being given to the animals, the food was rinsed and blotted with a paper towel and then weighed. After the experiment, the uneaten food was collected, dried, and weighed again. As in previous experiments (Botzer et al. 1991), the difference in weight was used as a measure of the weight of food eaten by the animals. As in previous experiments (Ziv et al. 1991), the time spent feeding was estimated by sampling animals every $5 \mathrm{~min}$, and noting whether or not they were actively feeding. Animals were weighed 10 min before and just after being observed, and the difference in weight also provided a measure of the quantity eaten. This experiment was performed in 5-L aquaria that contained a single Aplysia. The animals were transferred from the holding tanks to the experimental aquaria $24 \mathrm{~h}$ before start of the experiment.

\section{Egg-laying and addition of LHD homogenate}

The distal end of the large hermaphroditic duct (LHD) of $A$. fasciata, which contains tissue homologous to the atrial gland of A. californica, was removed from a single donor animal and was then homogenized in $1 \mathrm{~mL}$ of ASW. This volume was then injected into a single animal. This treatment induced egg-laying in all tested animals. The lips of animals were stimulated with inedible food starting from $10 \mathrm{~min}$ after treatment with the LHD homogenate. Stimulation was continued for the length of training in a yoked control animal, as described above for the experiment in which the lips were stimulated after treatment with histamine.

\section{Drugs and drug treatments}

Drugs injected into animals were prepared at concentrations 100 times more concentrated than the dose required, and are presented in the Results. The drugs were put into solution in ASW whose composition was $460 \mathrm{mM} \mathrm{NaCl}, 10 \mathrm{mM} \mathrm{KCl}, 11 \mathrm{mM} \mathrm{CaCl}$, $55 \mathrm{mM} \mathrm{MgCl}_{2}$, and $5 \mathrm{mM} \mathrm{NaHCO}_{3}$. Since the animals used in experiments were all $\sim 100 \mathrm{~g}$ in weight, $1 \mathrm{cc}$ of the drug in solution was injected into the hemocoele, thereby achieving a concentration within the animal that was appropriate to the experiment. Animals were injected with a drug 10 min before training. Injections were into the foot, to avoid hitting internal organs. Aplysia ganglia are embedded within a sheath, and the sheath is functionally part of the circulatory system (Coggeshall 1967; Chase 2002), assuring that substances injected into the hemolymph quickly circulate to the ganglia. Thus, the nervous system is likely to see concentrations that are 100 times more dilute than those injected, and that are similar to those used previously in in vitro preparations.

Histamine transmission was blocked with pyrilamine (Mepyramine; Sigma), a subtype selective antagonist of $\mathrm{H}_{1}$ histamine receptor. The concentration used $(10 \mu \mathrm{M})$ blocks the MCCs response to exogenous histamine in an in vitro cerebral ganglion (Jacklet et al. 2005).

Animals were also treated with $45 \mu \mathrm{M}$ of the NO donor SNAP (Sigma). This concentration causes memory that food is inedible when paired with lip stimulation (Katzoff et al. 2006), and also depolarizes the giant MCC neuron (Jacklet and Tieman 2004). In some experiments, animals were also treated with $0.37 \mathrm{mM}(100$ $\mathrm{mg} / \mathrm{kg}$ ) of the NO blocker L-NAME (Sigma). This concentration blocks learning that food is inedible (Katzoff et al. 2002). One experiment examined the effects of treatment with $5 \mu \mathrm{M}$ histamine. A previous study (Jacklet and Tieman 2004) showed that 20-50 $\mu \mathrm{M}$ histamine affects the MCC. We used a somewhat lower concentration because of the profound effects of histamine on Aplysia behavior (see below).

\section{Statistics}

Memory after training that food is inedible was tested by comparing data collected during training with comparable parameters measured during testing $24 \mathrm{~h}$ later. As in previous studies (Susswein et al. 1986; Botzer et al. 1998; Katzoff et al. 2002, 2006; Cohen-Armon et al. 2004; Lyons et al. 2005), paired $t$-tests were used for these comparisons, thereby allowing us to compare the same parameters within animals in naïve and trained individuals. In experiments examining memory after lip stimulation plus egglaying (Fig. 1), or after training with edible food (Fig. 3), or after training in isolation (Fig. 4), or after lip stimulation plus histamine (Fig. 6), comparable within-animal data before and after training were not available, since animals were trained with one procedure and then tested with another. For this reason, data on memory after training were compared to data from other animals, either naïve or trained. One-way analyses of variance, followed by a post hoc test, were performed.

\section{Acute MCC activity}

After injecting animals with $50 \%$ of their body weight of isotonic $\mathrm{MgCl}_{2}$, the cerebral ganglion was removed and placed in a solution of $75 \%$ isotonic $\mathrm{MgCl}_{2}, 25 \%$ ASW. The ganglion was not de-sheathed. A suction electrode was attached to one of the 
cerebral-buccal connectives (CBCs). Recordings from the CBC allowed us to monitor the activity of the MCC, a giant neuron that is excited via the release of both $\mathrm{NO}$ and histamine (McCaman and Weinreich 1985; Koh and Jacklet 1999). After replacing the medium with ASW, MCC activity was induced via the nonhydrolyzable cholinergic agonist carbamyl-choline (Carbachol, or CCh; $2 \times 10^{-4} \mathrm{M}$ ), which was applied for $5 \mathrm{~min}$ (Susswein et al. 1996; Katzoff et al. 2006). A total of eight trials of CCh application were run. These were separated from one another by 10-min intervals in which the cerebral ganglion was bathed in ASW. To determine how histamine affects the MCC activity induced by CCh, histamine $(5 \mu \mathrm{M})$ was applied along with CCh during the fourth and the fifth runs. After the fourth run, the CCh was washed and replaced with ASW containing histamine, to determine how these substances affect activity in the absence of CCh. Thus, the ganglion was exposed to histamine from the start of the fourth run in CCh, throughout the 10-min period between the fourth and the fifth runs, and was removed only after the fifth run. This procedure allowed us to compare the MCC responses to histamine to the background firing, as well as to the response to of the MCC to $\mathrm{CCh}$ alone. The MCC activity was quantified by measuring the rate of firing per minute.

\section{MCC chronic recording}

Animals (150-200 g) were placed in cooled seawater $\left(4^{\circ} \mathrm{C}\right)$ and then anesthetized with $10 \%$ of the body weight isotonic $\mathrm{MgCl}_{2}$. The body wall was opened close to the buccal ganglia, and one cerebral-buccal connective was cut close to the buccal ganglia. The cut end of the connective was sucked into a sleeve of polyethylene tubing (8025; A-M Systems), which was then cut just above the end of the nerve. A length of Pt-Ir wire (Medwire 10IR 9/497) with a bare ending was threaded into the cut end of the tubing, and placed in contact with the nerve. The cut end of the tubing was then sealed with cyanoacrylate glue (Instant Krazy Glue Gel). After the animal was sewn, the electrode was attached to the body wall with the glue. The recordings were made from freely behaving animals $24 \mathrm{~h}$ after the electrode was implanted.

\section{Acknowledgments}

We thank Maria Shefer and Hyla Aloush for help with some experiments, and David Levitan for comments on the manuscript. This work was supported by Israel Science Foundation Grants 357/ 02-17.2 and 506/09, and by an Israel Institute for Psychobiology Postdoctoral Fellowship to A.K.

\section{References}

Ahern GP, Klyachko VA, Jackson MB. 2002. c-GMP and S-nitrosylation: Two routes for modulation of neuronal excitability by NO. Trends Neurosci 25: $510-517$.

Antonov I, Ha T, Antonova I, Moroz LL, Hawkins RD. 2007. Role of nitric oxide in classical conditioning of siphon withdrawal in Aplysia. J Neurosci 27: 10993-11002.

Arch S, Smock T, Gurvis R, McCarthy C. 1978. Atrial gland induction of egg laying response in Aplysia californica. J Comp Physiol 128: 67-70.

Bacciottini L, Passani MB, Mannaioni PF, Blandina P. 2001. Interactions between histaminergic and cholinergic systems in learning and memory. Behav Brain Res 124: 183-194.

Baldi E, Bucherelli C, Schunack W, Cenni G, Blandina P, Passani MB. 2005. The H3 receptor protean agonist proxyfan enhances the expression of fear memory in the rat. Neuropharmacology 48: 246-251.

Baratti CR, Kopf SR. 1996. A nitric oxide synthase inhibitor impairs memory storage in mice. Neurobiol Learn Mem 65: 197-201.

Baratti CM, Boccia MM, Blake MG, Acosta GB. 2008. Reactivated memory of an inhibitory avoidance response in mice is sensitive to a nitric oxide synthase inhibitor. Neurobiol Learn Mem 89: 426-440.

Bernaerts P, Lamberty Y, Tirelli E. 2004. Histamine H3 antagonist thioperamide dose-dependently enhances memory consolidation and reverses amnesia induced by dizocilpine or scopolamine in a one-trial inhibitory avoidance task in mice. Behav Brain Res 154: 211-219.

Botzer D, Blumberg S, Ziv I, Susswein AJ. 1991. Common regulation of feeding and mating in Aplysia fasciata: Pheromones released by mating and by egg cordons increase feeding behavior. Behav Neural Biol 56: 251-261.
Botzer D, Markovich S, Susswein AJ. 1998. Multiple memory processes following training that a food is inedible in Aplysia. Learn Mem 5: 204 219.

Bredt DS, Snyder SH. 1992. Nitric oxide, a novel neuronal messenger. Neuron 8: 3-11.

Brembs B, Lorenzetti FD, Reyes FD, Baxter DA, Byrne JH. 2002. Operant reward learning in Aplysia: Neuronal correlates and mechanisms. Science 296: $1706-1709$.

Brembs B, Baxter DA, Byrne JH. 2004. Extending in vitro conditioning in Aplysia to analyze operant and classical processes in the same preparation. Learn Mem 11: 412-420.

Chase R. 2002. Behavior and its neural control in gastropod molluscs. Oxford University Press, Oxford, UK.

Chiel HJ, Susswein AJ. 1993. Learning that food is inedible in freely behaving Aplysia californica. Behav Neurosci 107: 327-338.

Chiel HJ, Weiss KR, Kupfermann I. 1986. An identified histaminergic neuron modulates feeding motor circuitry in Aplysia. J Neurosci 6: 24272450.

Chiel HJ, Weiss KR, Kupfermann I. 1990. Multiple roles of a histaminergic afferent neuron in the feeding behavior of Aplysia. Trends Neurosci 13: 223-227.

Coggeshall RE. 1967. A light and electron microscope study of the abdominal ganglion of Aplysia californica. J Neurophysiol 30: 1263-1287.

Cohen-Armon M, Visochek L, Katzoff A, Levitan D, Susswein AJ, Klein R, Valbrun M, Schwartz JH. 2004. Long-term memory requires polyADPribosylation. Science 304: 1820-1822.

Edwards TM, Rickard NS. 2007. New perspectives on the mechanisms through which nitric oxide may affect learning and memory processes. Neurosci Biobehav Rev 31: 413-425.

Eidi M, Zarrindast MR, Eidi A, Oryan S, Parivar K. 2003. Effects of histamine and cholinergic systems on memory retention of passive avoidance learning in rats. Eur J Pharmacol 465: 91-96.

Elste A, Koester J, Shapiro E, Panula P, Schwartz JH. 1990. Identification of histaminergic neurons in Aplysia. J Neurophysiol 64: 736-744.

Horn CC, Benjamin PR, Weiss KR, Kupfermann I. 1999. Decrement of the response of a serotonergic modulatory neuron (the metacerebral cell) in Aplysia, during repeated presentation of appetitive (food) stimuli. Neurosci Lett 267: 161-164.

Jacklet JW. 1995. Nitric oxide is used as an orthograde cotransmitter at identified histaminergic synapses. J Neurophysiol 74: 891-895.

Jacklet JW, Tieman DG. 2004. Nitric oxide and histamine induce neuronal excitability by blocking background currents in neuron MCC of Aplysia. J Neurophysiol 91: 656-665.

Jacklet JW, Grizzaffi J, Tieman D. 2005. Sodium and calcium currents contribute to increased excitability induced by serotonin, nitric oxide, and histamine in neuron MCC of Aplysia. In Program No. 754.8, 2005 Abstract Viewer/Itinerary Planner. Society for Neuroscience, Washington, DC.

Katzoff A, Ben-Gedalya Z, Susswein AJ. 2002. Nitric oxide is necessary for multiple memory processes after learning that a food is inedible in Aplysia. J Neurosci 22: 9581-9594.

Katzoff A, Ben-Gedalya T, Hurwitz I, Miller N, Susswein YZ, Susswein AJ. 2006. Nitric oxide signals that Aplysia have attempted to eat, a necessary component of memory formation after learning that food is inedible. J Neurophysiol 96: 1247-1257.

Kemenes I, Kemenes G, Andrew RJ, Benjamin PR, O'Shea M. 2002. Critical time-window for NO-cGMP-dependent long-term memory formation after one-trial appetitive conditioning. J Neurosci 22: 1414-1425.

Koh H-Y, Jacklet JW. 1999. Nitric oxide stimulates cGMP production and mimics synaptic responses in metacerebral neurons of Aplysia. J Neurosci 19: 3618-3626.

Komater VA, Buckley MJ, Browman KE, Pan JB, Hancock AA, Decker MW, Fox GB. 2005. Effects of histamine H3 receptor antagonists in two models of spatial learning. Behav Brain Res 159: 295-300.

Korneev SA, Straub V, Kemenes I, Korneeva EI, Ott SR, Benjamin PR, O'Shea M. 2005. Timed and targeted differential regulation of nitric oxide synthase (NOS) and anti-NOS genes by reward conditioning leading to long-term memory formation. J Neurosci 25: 1188-1192.

Kupfermann I. 1968. A circadian locomotor rhythm in Aplysia californica. Physiol Behav 3: 179-181.

Kupfermann I. 1974. Feeding behavior in Aplysia: A simple system for the study of motivation. Behav Biol 10: 1-26.

Kupfermann I, Pinsker HM. 1968. A behavioral modification of the feeding reflex in Aplysia californica. Commun Behav Biol 2: 13-17.

Kupfermann I, Weiss KR. 1982. Activity of an identified serotonergic neuron in free moving Aplysia correlates with behavioral arousal. Brain Res 241: 334-337.

Kupfermann I, Cohen JL, Mandelbaum DE, Schonberg M, Susswein AJ, Weiss KR. 1979. Functional role of serotonergic neuromodulation in Aplysia. Fed Proc 38: 2095-2102.

Lechner HA, Baxter DA, Byrne JH. 2000. Classical conditioning of feeding in Aplysia: I. Behavioral analysis. J Neurosci 20: 3369-3376. 
Levy M, Susswein AJ. 1999. Separate effects of a classical conditioning procedure on respiratory pumping, swimming and inking in Aplysia fasciata. Learn Mem 6: 21-36.

Lewin MR, Walters ET. 1999. Cyclic GMP pathway is critical for inducing long-term sensitization of nociceptive sensory neurons. Nat Neurosci 2 18-23.

Lorenzetti FD, Mozzachiodi R, Baxter DA, Byrne JH. 2006. Classical and operant conditioning differentially modify the intrinsic properties of an identified neuron. Nat Neurosci 9: 17-19.

Lyons LC, Rawashdeh O, Katzoff A, Susswein AJ, Eskin A. 2005. Circadian modulation of complex learning in diurnal and nocturnal Aplysia. Proc Natl Acad Sci 102: 12589-12594.

McCaman RE, Weinreich D. 1985. Histaminergic synaptic transmission in the cerebral ganglion of Aplysia. J Neurophysiol 53: 1016-1037.

McGaugh JL. 2004. The amygdala modulates the consolidation of memories of emotionally arousing experiences. Annu Rev Neurosci 27: 1-28.

Meffert MK, Calakos NC, Scheller RH, Schulman H. 1996. Nitric oxide modulates synaptic vesicle docking fusion reactions. Neuron 16: 12291236.

Miller N, Katzoff A, Susswein AJ. 2008. NO induces aspects of egg-laying behavior in Aplysia. I Exp Biol 211: 2388-2396.

Miller N, Saada R, Fishman S, Hurwitz I, Susswein AJ. 2009. Arginine regulates Aplysia feeding via background nitric oxide release. In Program No. 888.5/GG11, Neuroscience Meeting Planner. Society for Neuroscience, Chicago, IL.

Moroz LL. 2006. Localization of putative nitrergic neurons in peripheral chemosensory areas and the central nervous system of Aplysia californica. J Comp Neurol 495: 10-20.

Mozzachiodi R, Lechner HA, Baxter DA, Byrne JH. 2003. In vitro analog of classical conditioning of feeding behavior in Aplysia. Learn Mem 10: 478-494.

Müller U. 1996. Inhibition of nitric oxide synthase impairs a distinct form of long-term memory in the honeybee, Apis mellifera. Neuron 16: 541549 .

Nargeot R, Baxter DA, Byrne JH. 1997. Contingent-dependent enhancement of rhythmic motor patterns: An in vitro analog of operant conditioning. J Neurosci 17: 8093-8105.

Nargeot R, Petrissans C, Simmers J. 2007. Behavioral and in vitro correlates of compulsive-like food seeking induced by operant conditioning in Aplysia. J Neurosci 27: 8059-8070.

Ram JL. 1982. Aplysia egg-laying hormone increases excitatory input into a retractor muscle of the buccal mass. Brain Res 236: 505-510.

Ram JL. 1983. Neuropeptide activation of an identifiable buccal ganglion motoneuron in Aplysia. Brain Res 288: 177-186.

Robertson JD, Bonaventura J, Kohm A. 1995. Nitric oxide synthase inhibition blocks octopus touch learning without producing sensory or motor dysfunction. Proc R Soc Lon B 261: 167-172.
Schwarz M, Susswein AJ. 1986. Identification of the neural pathway for reinforcement of feeding when Aplysia learn that food is inedible. J Neurosci 6: 1528-1536.

Schwarz M, Susswein AJ. 1993. Restoration of learning and memory that food is inedible in isolated Aplysia by some stimuli producing food arousal. Soc Neurosci Abstr 19: 1-3.

Schwarz M, Markovich S, Susswein AJ. 1988. Parametric features of inhibition of feeding in Aplysia by associative learning, satiation and sustained lip stimulation. Behav Neurosci 102: 124-133.

Schwarz M, Feldman E, Susswein AJ. 1991. Variables affecting long-term memory of learning that a food is inedible in Aplysia. Behav Neurosci 105: 193-201.

Serfözö Z, Szentmiklósi AJ, Elekes K. 2008. Characterization of nitric oxidergic neurons in the alimentary tract of the snail Helix pomatia L.: Histochemical and physiological study. J Comp Neurol 506: 801-821.

Squire LR, Kandel E. 2000. Memory: From mind to molecules. Owl Books, New York.

Stuart DK, Strumwasser F. 1980. Neuronal sites of action of a neurosecretory peptide, egg-laying hormone, in Aplysia californica. J Neurophysiol 43: 499-519.

Susswein AJ, Gev S, Feldman E, Markovich S. 1983. Activity patterns and time budgeting of Aplysia fasciata in field and laboratory conditions. Behav Neural Biol 39: 203-220.

Susswein AJ, Schwarz M, Feldman E. 1986. Learned changes of feeding behavior in Aplysia in response to edible and inedible foods. J Neurosci 6: 1513-1527.

Susswein AJ, Rosen SC, Gapon S, Kupfermann I. 1996. Characterization of buccal motor programs elicited by a cholinergic agonist applied to the cerebral ganglion of Aplysia californica. J Comp Physiol [A] 179: 509_ 524.

Susswein AJ, Katzoff A, Miller N, Hurwitz I. 2004. Nitric oxide and memory. Neuroscientist 10: 153-162.

Teyke T, Weiss KR, Kupfermann I. 1991. Egg-laying hormone inhibits a neuron (C-PR) involved in multiple manifestations of food-induced arousal in Aplysia. Brain Res 552: 248-254.

Walters ET, Carew TJ, Kandel ER. 1981. Associative learning in Aplysia: Evidence for conditioned fear in an invertebrate. Science 211: 504-506.

Weiss KR, Chiel HJ, Kupfermann I. 1986a. Sensory function and gating of histaminergic neuron C2 in Aplysia. J Neurosci 6: 2416-2424.

Weiss KR, Shapiro E, Kupfermann I. 1986b. Modulatory synaptic actions of an identified histaminergic neuron on the serotonergic metacerebral cell of Aplysia. J Neurosci 6: 2393-2402.

Ziv I, Botzer D, Markovich S, Susswein AJ. 1991. Effects of conspecifics on feeding in Aplysia fasciata. Behav Neural Biol 55: 108-113.

Received September 8, 2009; accepted in revised form October 23, 2009. 


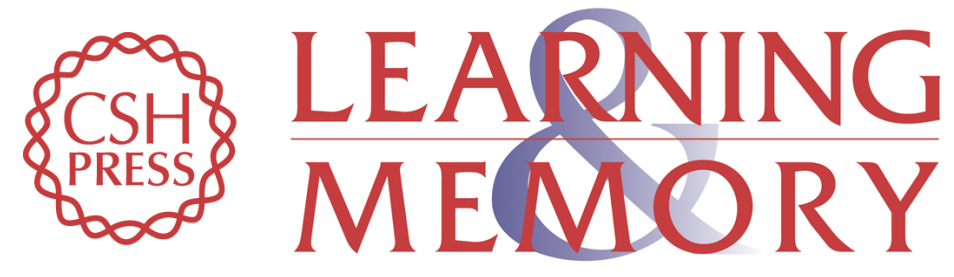

\section{Nitric oxide and histamine signal attempts to swallow: A component of learning that food is inedible in Aplysia}

Ayelet Katzoff, Nimrod Miller and Abraham J. Susswein

Learn. Mem. 2010, 17:

Access the most recent version at doi:10.1101//m.1624610

References This article cites 67 articles, 21 of which can be accessed free at: http://learnmem.cshlp.org/content/17/1/50.full.htmI\#ref-list-1

License

Email Alerting Receive free email alerts when new articles cite this article - sign up in the box at the Service top right corner of the article or click here. 